Iranica Journal of Energy \& Environment 2 (4): 382-389, 2011

ISSN 2079-2115

IJEE an Official Peer Reviewed Journal of Babol Noshirvani University of Technology

DOI:10.5829/idosi.ijee.2011.02.04.3098

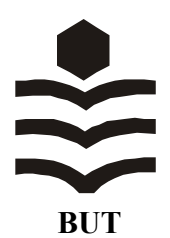

\title{
Turbulent Flow Measurement in Vortex Settling Basin
}

\author{
Jafar Chapokpour, Javad Farhoudi and Ebrahim Amiri Tokaldani
}

\author{
Department of Irrigation and Reclamation Engineering, \\ College of Agricultural Engineering and Technology, University of Tehran, Karaj, Iran
}

(Received: October 26, 2011; Accepted: December 19, 2011)

\begin{abstract}
This paper presents the findings of an experimental study on the three-dimensional turbulent flow field in vortex settling basin. An ADV (Acoustic Doppler Velocity Meter) were used to catch 3D velocity components inside the basin. Detailed measurements of time-averaged velocity components, turbulent intensity components and turbulent kinetic energy were determined at different radial sections of chamber. Also the normalized time averaged absolute velocity of 3D components in contour type exhibition were conducted and it was found that the absolute velocity generally is influenced by u component of flow. It trends from high magnitude in basin center to the constant magnitude in basin side wall. The normalized turbulent intensity of three components was investigated individually. It was found that intensity of $3 \mathrm{D}$ components in vicinity of central air core is higher than other regions, decreasing by moving towards basin sidewall except for the sections that influenced directly by entrance flow jet and sidewall exiting overflow. The results of turbulence kinetic energy also had the same interpretation like turbulence intensity and affected by the same boundary conditions which cover turbulence intensity of 3 velocity components overly.
\end{abstract}

Key words: Vortex flow $\cdot 3 \mathrm{D}$ Velocity distribution $\cdot$ Turbulence intensity $\cdot$ Turbulence kinetic energy

\section{INTRODUCTION}

Sediment laden flows are capable to transport and deposit a considerable rate of sediment load in the conveyance channels which results in reduction of conveyance capacity of the system. Therefore, measures are to be taken to exclude the sediment particles from the diverted flow into the irrigation canals. Different types of sediment extractors/excluders, such as tunnel type, vortex tubes, rectangular settling basins and vortex type settling basins are often employed for this purpose. In recent years the vortex settling basin (VSB) has attracted a considerable interest among the water engineers. The VSB is a continuous device which applies a certain fraction of flow for flushing the sediment particles out of the diverted stream [1]. VSB utilizes centrifugal forces to generate a vortex motion around its central axis to remove sediment particles from the incoming flow by means of secondary currents in the chamber through the central flushing orifice [2]. In this device the high velocity flow is introduced tangentially into cylindrical basin having an orifice at the center of its bottom [3]. Resulting secondary flow causes the flow layers adjacent to the floor of the basin moving towards the central outlet orifice. Therefore, the sediment particles reaching the center of the chamber could be flushed out continuously through the orifice and a relatively sediment free water would leave the basin through its overflow weir crest [4].

A set of VSBs placed in series are used when the inlet-canal discharge is too large to be handled by a single VSB [5]. For lengthening of particle path inside the basin, the use of deflector vane has been introduced by some investigators. Chrysostomou [6] and Rea [7] have shown that provision of the deflector ensures maximum residence time and that the swirls forming as a result of secondary flow are minimum.

The size of a VSB is very small, compared with conventional settling basins treating the same volume of water and sediment load [8].

The flow behavior in this device is so complex due to turbulent nature and secondary currents of flow field. It is believed that better understanding of sediment trapping

Corresponding Author: Jafar Chapokpour, Department of Irrigation and Reclamation Engineering, College of Agricultural Engineering and Technology, University of Tehran, Karaj, Iran. Tel: +989148547010.

Fax: +982612231787 . 
in such structures is dependent to understanding of turbulence nature of flow in the basin. Limited researches have been carried out previously on flow structures of these type extractors. However, turbulence characteristics in the basin remain unexplored.

Most of previous investigators in their experimental studies tried to focus on the trap efficiency of the vortex settling basin and express an appropriate relationship for its estimation.

Secondary currents were generated in the vortex settling basin as a consequences of the effects raised from (i) entering water jet, (ii) over fall water jet from the curved weir crest and (iii) the bed slope of the basin towards the central orifice [9].

The goal of present study was to investigate the three-dimensional turbulent flow field in the cylindrical vortex chamber as a sediment extractor device using Acoustic Doppler Velocity Meter (ADV). In this research, a different discharge rather than previous investigation that has done previously by Chapokpour and Farhoudi [10] was employed to basin and detailed measurements and computation of time averaged velocity components, turbulence intensity components and turbulence kinetic energy components at different radial sections of chamber were detected then depicted.

\section{MATERIALS AND METHODS}

Experimental Layout and Methodology: The experiments were carried out in a physical model of the vortex settling basin with the characteristics shown in Table 1 and schematically depicted in Fig. 1.

The tests were performed in a configuration in which the angular distance of inlet and overflow outlet was 0 degree as recommended by Paul et al. [11]. To maintain a tangential inlet flow jet in the vortex basin, a diaphragm was installed across the entrance channel at a level of $0.12 \mathrm{~m}$ from the canal bed. Water was then supplied from a constant head tank connected through upstream stilling tank to the circulating water supply system of the laboratory where the incoming flow was regulated by means of a turning valve. Precautions were made to avoid large eddies and disturbances at the free surface of water in upstream stilling tank. The discharge from overflow weir and flushing orifice were measured by means of a pre-calibrated sharp crested rectangular weir and a Vnotch respectively.

The velocities were measured in eight radial sections at intervals of $45^{\circ}$ from the origin, as shown in Fig. 2.

At each radial section 56 points were selected in a grid of velocity measurement, as demonstrated in Fig. 2, resulting in a total of 448 measuring points inside the chamber.

Collected velocity data were filtered and analyzed and then 2D streamlines in the radial and horizontal sections were drawn and then interpreted.

Figure 2. Grid of data collection for velocity measurement with location of entrance and overflow weir

\section{RESULTS AND DISCUSSION}

Velocity Distribution: The time averaged velocity distribution in polar coordinate system is represented by $(\mathbf{u}, \mathbf{v}, \mathbf{w})$ where: $\mathbf{u}$ : tangential velocity, $\mathbf{v}$ : radial velocity, $\mathbf{w}$ : vertically velocity (Fig. 3). Normalization of all velocity components were done with basin average entrance velocity (U). Hence for detection of secondary currents and understanding of its influence on trapping action, the normalized time average velocity distribution in RZ (radial) planes according to normalized velocity vectors of $\hat{\mathrm{v}}=\frac{\mathrm{v}}{\mathrm{U}}, \hat{\mathrm{w}}=\frac{\mathrm{w}}{\mathrm{U}}$ were depicted. The velocity vector of mentioned components are equal to $\sqrt{\hat{\mathrm{v}}^{2}+\hat{\mathrm{w}}^{2}}$ with angle of $\left(\arctan \frac{\hat{\mathrm{w}}}{\hat{\hat{v}}}\right)$. Then the streamlines coincident to velocity vector, were depicted and different types of flow patterns were observed (Fig. 3).

As is shown in Fig 3, various types of clockwise and anticlockwise vortices and some sink points combined with each other in different sections of basin were found. It is clear that formation of these flow patterns are totally dependent on position of every radial section proportional to boundary conditions of basin (like entrance flow jet, overflow exiting weir jet and flushing jet of central orifice). So it is evident that combination of these flow patterns, tendency and intensity of them to

Table 1: Characteristics of settling basin

\begin{tabular}{|c|c|c|c|c|c|c|c|}
\hline $\begin{array}{l}\text { Height of } \\
\text { chamber } H(\mathrm{~m})\end{array}$ & $\begin{array}{l}\text { Diameter of central } \\
\text { orifice } d_{o}(\mathrm{~m})\end{array}$ & $\begin{array}{l}\text { Type of overflow } \\
\text { weir } L_{l}(\mathrm{~m})\end{array}$ & $\begin{array}{l}\text { Diameter of } \\
\text { chamber } d(\mathrm{~m})\end{array}$ & $\begin{array}{l}\text { Basin depth at } \\
\text { periphery } h_{2}(\mathrm{~m})\end{array}$ & $\begin{array}{l}\text { Width of inlet } \\
\text { channel } B(\mathrm{~m})\end{array}$ & $\begin{array}{l}\text { Length of } \\
\text { inlet channel (m) }\end{array}$ & $\begin{array}{l}\text { Slope of inlet } \\
\text { channel } S \%\end{array}$ \\
\hline 0.7 & 0.075 & $\begin{array}{l}\text { Circular overflow weir } \\
\text { with crest length of } 0.8\end{array}$ & 1.5 & 0.06 & 0.3 & 6 & 0.045 \\
\hline
\end{tabular}


Iranica J. Energy \& Environ., 2 (4): 382-389, 2011
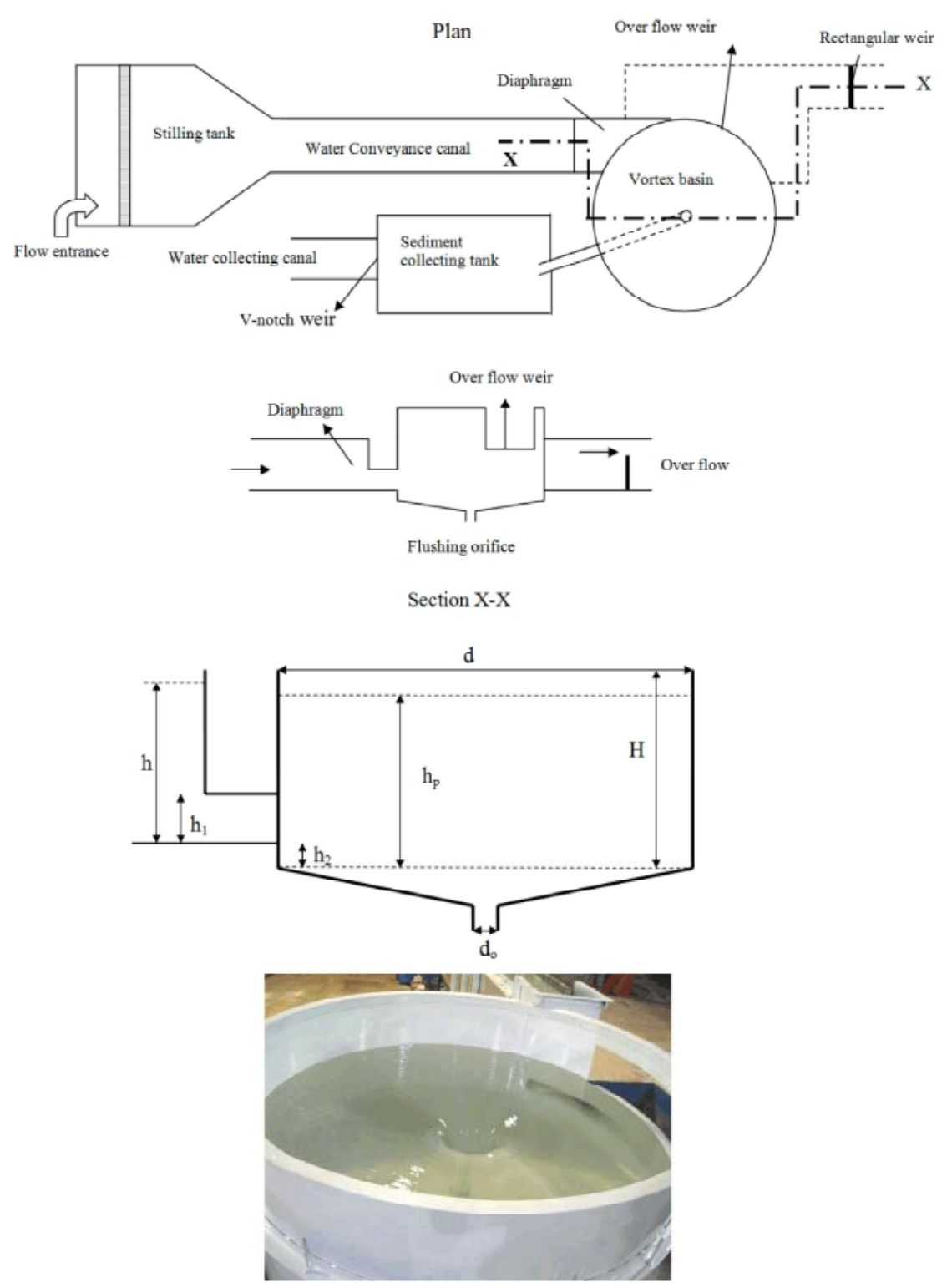

Fig. 1: Schematic layout and parameters of vortex settling basin, used in the research
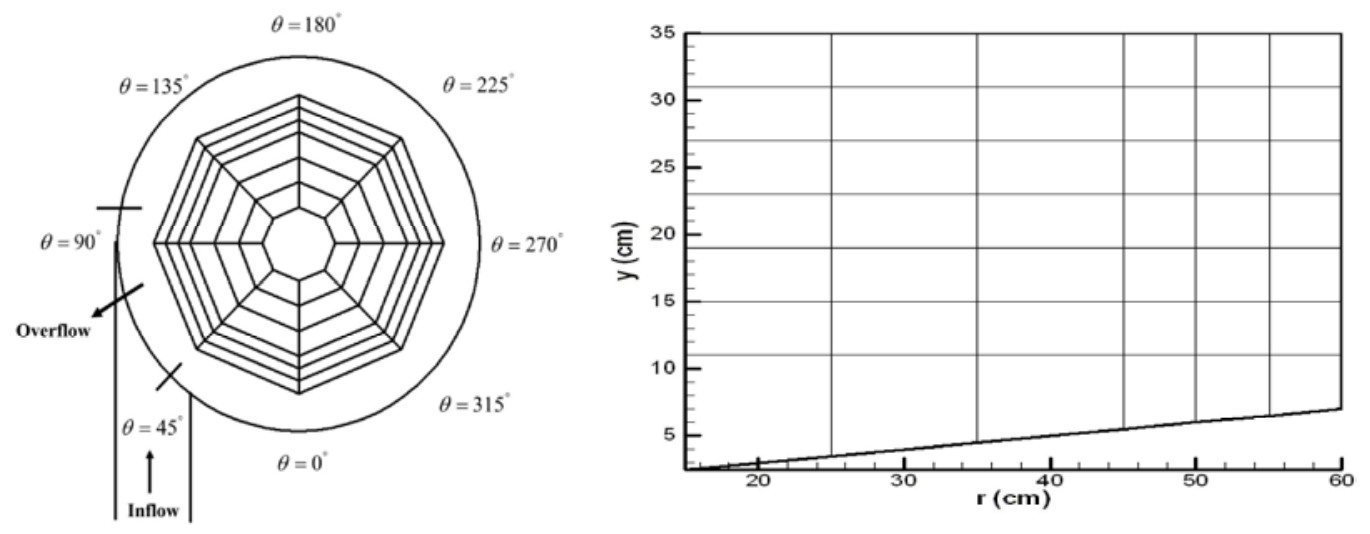

Fig. 2: Grid of data collection for velocity measurement with location of entrance and overflow weir 


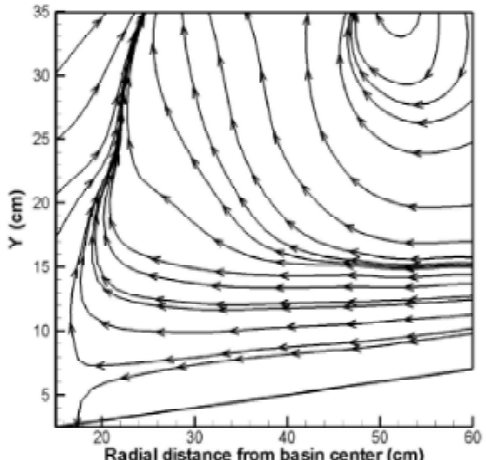

$\left(0^{\circ}\right), \mathrm{A}$

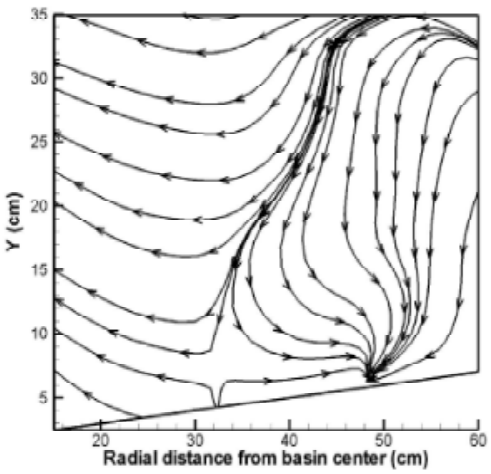

$\left(135^{\circ}\right) . \mathrm{D}$

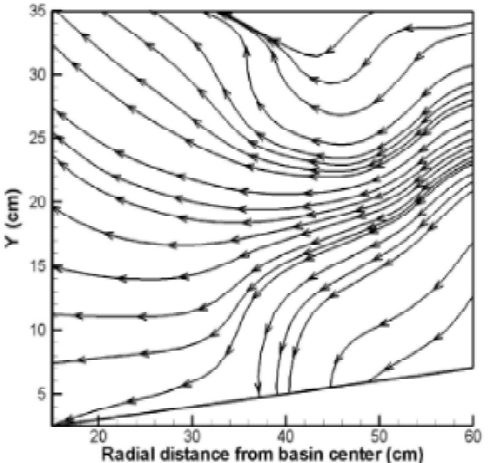

$\left(45^{\circ}\right), \mathrm{B}$

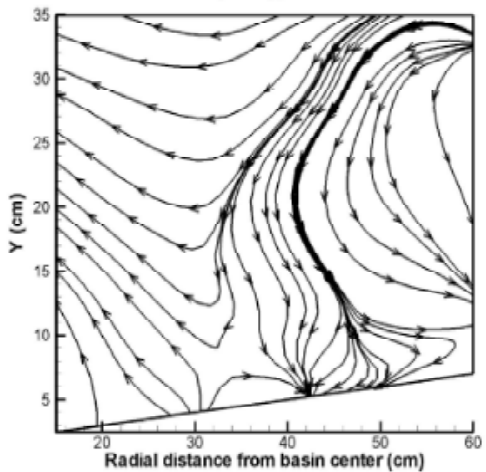

$\left(180^{\circ}\right), \mathrm{E}$

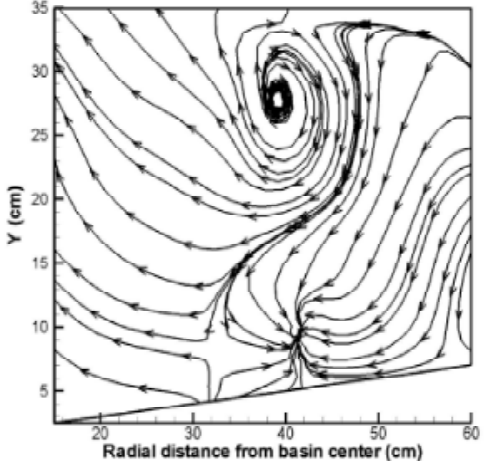

$\left(90^{\circ}\right) . \mathrm{C}$

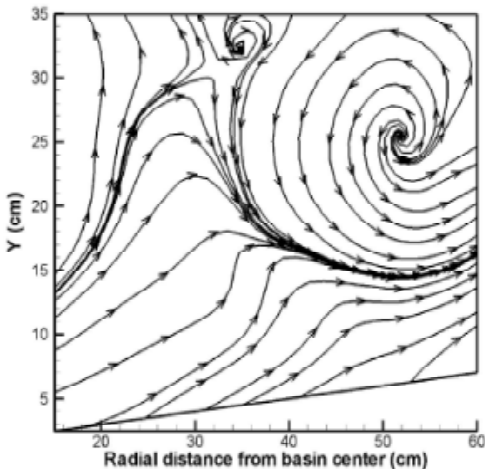

$\left(225^{\circ}\right), \mathrm{F}$

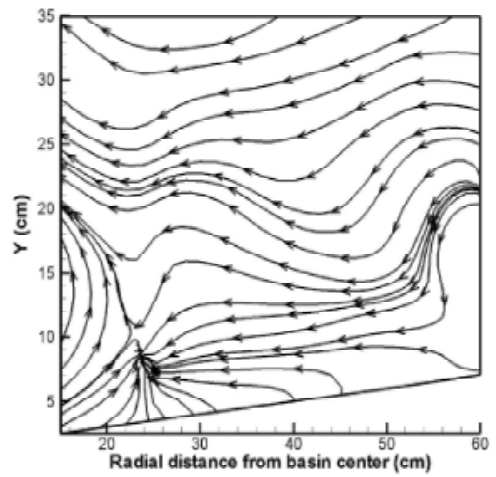

$\left(270^{\circ}\right), \mathrm{G}$

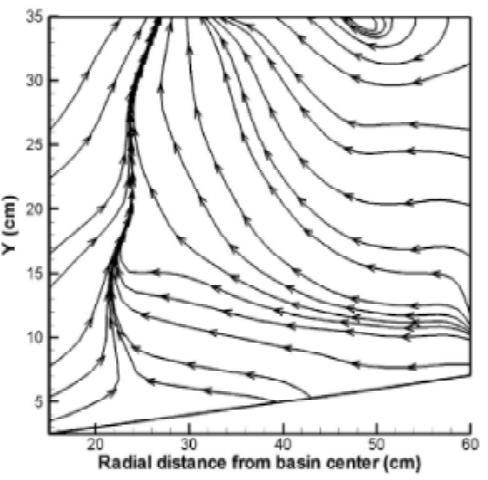

$\left(315^{\circ}\right), \mathrm{H}$

Fig. 3: Detection of flow types in radial sections of basin

the central air core or side wall of basin will have a great influence on sediment trapping action of the device, exhibiting the importance of basin regions in removing sediment particles.

At section of $\mathrm{A}$ the velocity vectors with its magnitude and direction exhibit general propagation towards central air core with a weak tendency for generation of clockwise vortex but the vectors at the radial distance of $15 \mathrm{~cm}$ have upward direction against general tendency of currants, causing upward deflection of streamlines in vicinity of air core (Fig. 3). At the section of B that was positioned at the middle of overflow exiting jet and influenced directly and strongly with entrance/ exiting flow jets, general propagation in previous section exist again but the magnitude of vectors in basin sidewall is more than all sections, weakening the mentioned clockwise tendency and streamlines deflection in air core vicinity. By moving to the $\mathrm{C}$ section mentioned clockwise vortex and a sink point generated in a different position rather than A section due to decrease of magnitude and direction of velocity vectors. The position of sink point is adjacent to the basin bed in radial distance of $40 \mathrm{~cm}$ and 


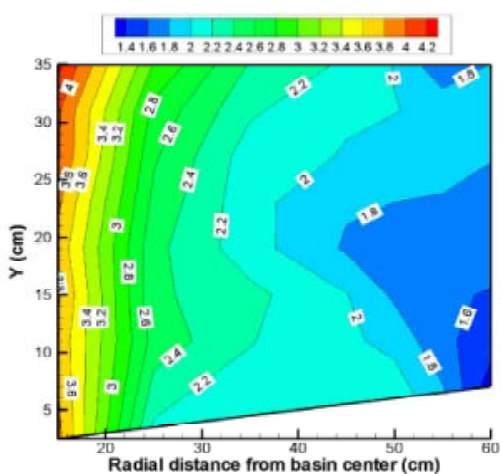

$\left(0^{\circ}\right), \mathrm{A}$

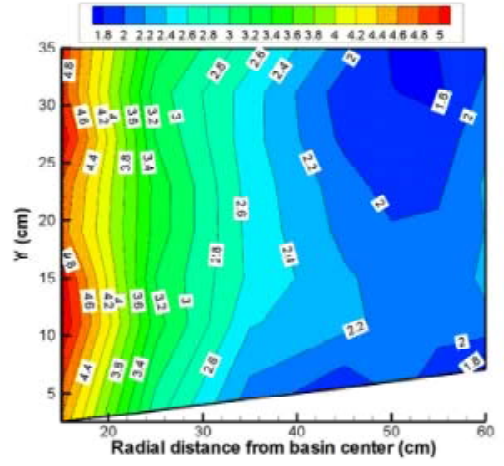

$\left(135^{\circ}\right), \mathrm{D}$

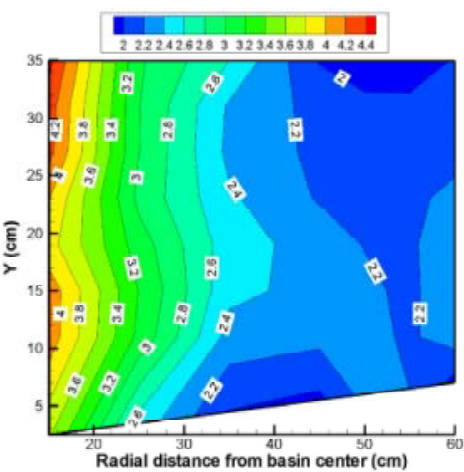

$\left(45^{\circ}\right), \mathrm{B}$

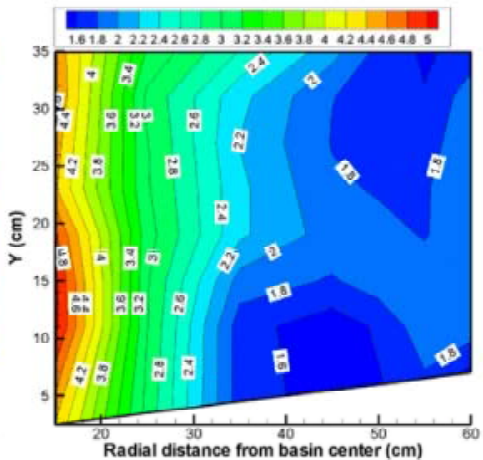

$\left(180^{\circ}\right), \mathrm{E}$

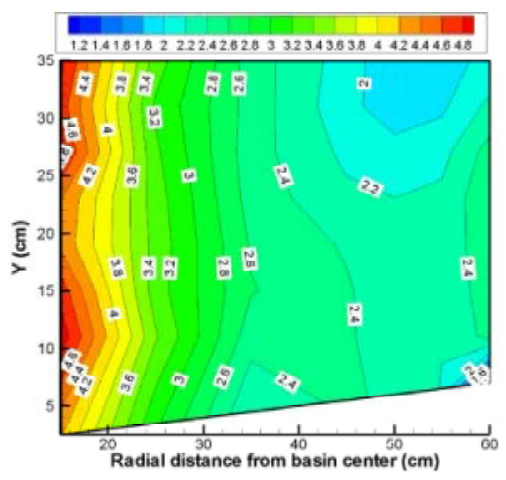

$\left(90^{\circ}\right), \mathrm{C}$

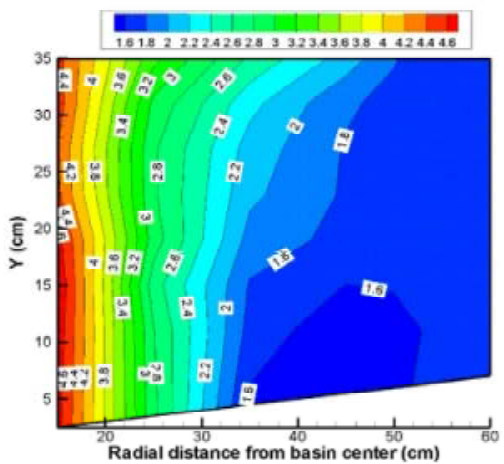

$\left(225^{\circ}\right), \mathrm{F}$

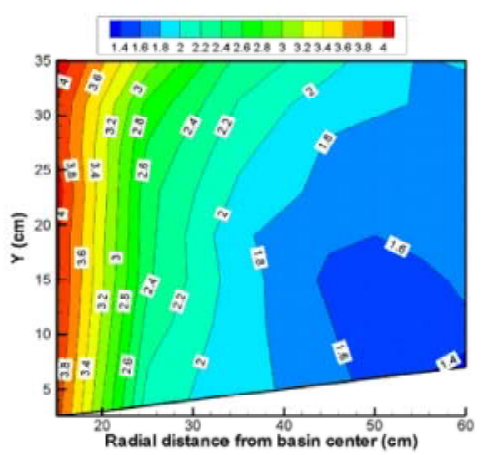

$\left(270^{\circ}\right), \mathrm{G}$

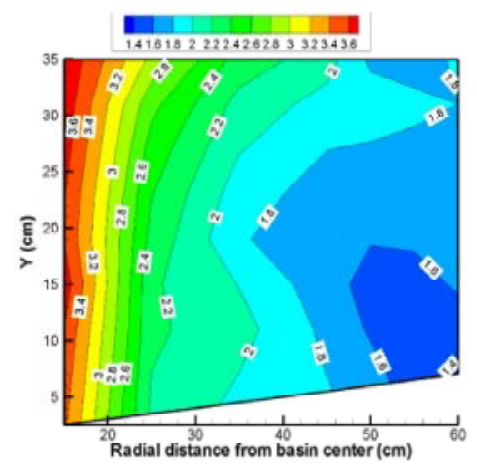

$\left(315^{\circ}\right), \mathrm{H}$

Fig. 4: Depiction of time averaged absolute velocity

height of $8 \mathrm{~cm}$. it is noteworthy to mention that a weak trend for generation of mentioned sink point also were existed in B section, continued to E section. By moving across the D-F sections diminishing of sink point and formation of anticlockwise vortex adjacent to the sidewall of basin is a prominent phenomenon, having weak intensity of vortex proportional to magnitude of velocity vectors. At the G-H sections propagations of streamlines towards central air core and flushing of anticlockwise vortex and upward deflecting of them at the $\mathrm{H}$ section are dominant. Generally it could be expressed that by moving along with radial sections tendency for formation and flushing of different type flow patterns like clockwise and anticlockwise vortices and sink points were observed proportional to the position of section to the chamber boundary conditions which may play positive or negative role to the extracting process of basin.

The normalized absolute time averaged velocity contours $\left(\hat{V}=\sqrt{\hat{u}^{2}+\hat{v}^{2}+\hat{w}^{2}}\right)$ at different radial sections are displayed in Fig. 4, Having high magnitude of velocity around central air core and lower magnitude around sidewall of basin. The absolute velocity dominantly influenced by $\mathbf{u}$ component of 3D velocity because of higher magnitude of it rather than $\mathbf{v}, \mathbf{w}$ components. 
The $\mathrm{u}$ component in this type vortex flow fields trends from high magnitude in the central region to constant magnitude in the basin wall zones. As is shown in Fig. 4, in all sections absolute velocity gradient in central zones is higher and a notable diversity between different sections does not exist. Additionally it should be mentioned that absolute velocity gradient generally is dependent to radial distance from basin center (like tangentially velocity) and notable velocity changes in the height of basin are not indicated in Fig. 4. It is interesting to mention that at the section of $\mathrm{C}$, positioned with 90 degree distance from the origin, the distribution of absolute velocity is unifier than other sections affected by entrance flow jet, having lower differences between central part of basin and side wall region.

Turbulence Intensity and Turbulent Kinetic Energy: The turbulence intensity often referred to as turbulence level of flow field and is defined as the ratio of the rootmean-square of the velocity fluctuations to the mean

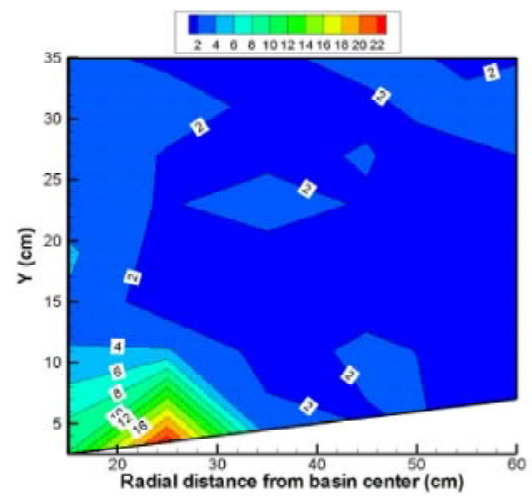

$\left(0^{\circ}\right), A$

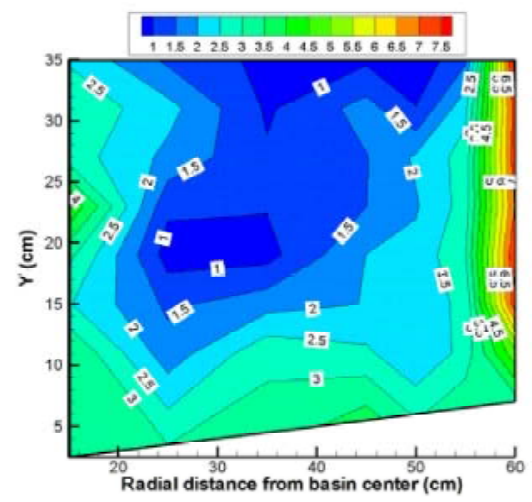

$\left(135^{\circ}\right), \mathrm{D}$

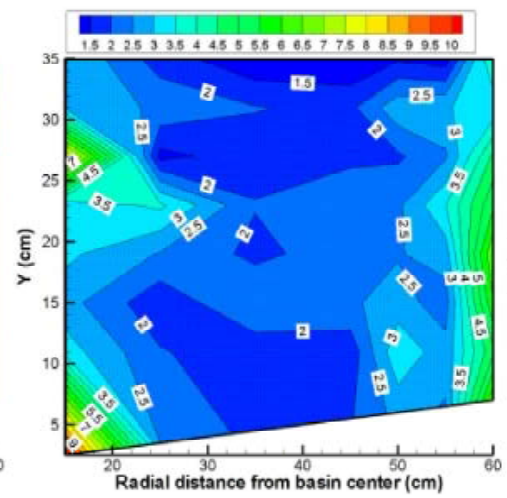

$\left(45^{\circ}\right), \mathrm{B}$

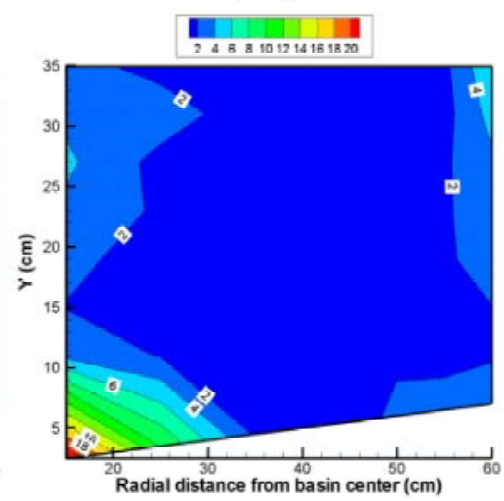

$\left(180^{\circ}\right), \mathrm{E}$

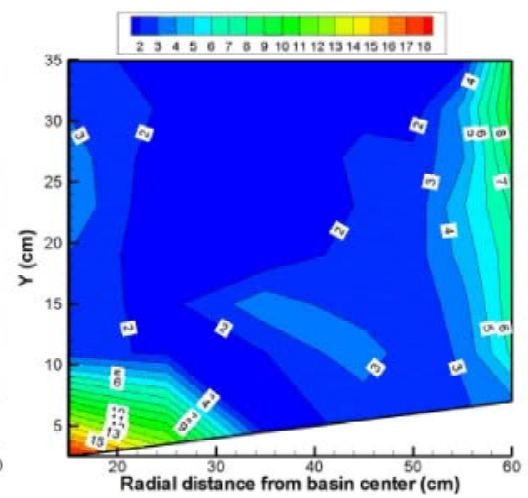

$\left(90^{\circ}\right), \mathrm{C}$

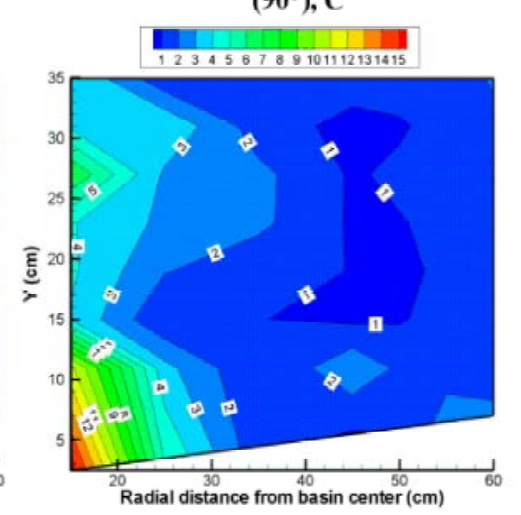

$\left(225^{\circ}\right), \mathrm{F}$

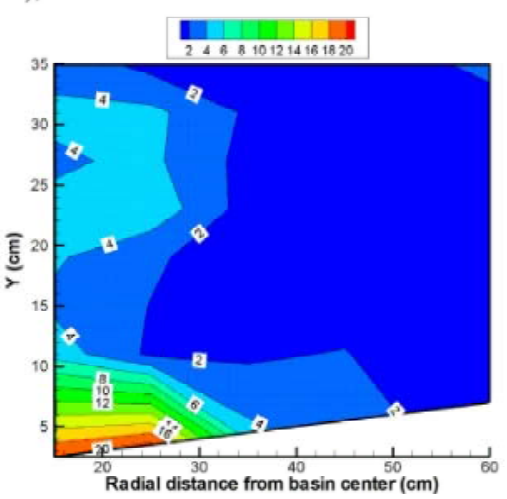

$\left(270^{\circ}\right), G$

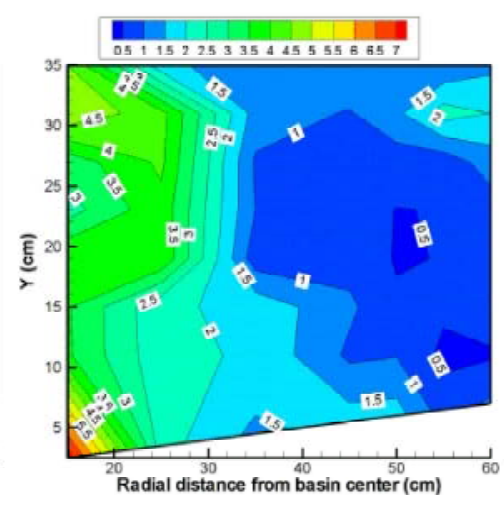

$\left(315^{\circ}\right), \mathrm{H}$

Fig. 5: Computation of turbulence kinetic energy along with various radial sections 
entrance flow velocity. In these experiments the turbulent velocity fluctuations $\mathrm{u}^{\prime}, \mathrm{v}^{\prime}$ and $\mathrm{w}^{\prime}$ can be determined by a large set of instantaneous velocities using $\mathrm{u}^{\prime}=\mathrm{u}_{\mathrm{i}}-\overline{\mathrm{u}}, \mathrm{v}^{\prime}=\mathrm{v}_{\mathrm{i}}-\overline{\mathrm{v}}, \mathrm{w}^{\prime}=\mathrm{w}_{\mathrm{i}}-\overline{\mathrm{w}} \quad$ respectively. The terms $\overline{\mathrm{u}}, \overline{\mathrm{v}}, \overline{\mathrm{w}}$, also can be obtained from $\overline{\mathrm{u}}=\Sigma_{1}^{\mathrm{n}} \mathrm{u}_{\mathrm{i}}$, $\overline{\mathrm{v}}=\Sigma_{1}^{\mathrm{n}} \mathrm{v}_{\mathrm{i}}, \overline{\mathrm{w}}=\Sigma_{1}^{\mathrm{n}} \mathrm{w}_{\mathrm{i}} \quad$ respectively. At the tangential distribution of normalized stream wise turbulent intensity component $\mathrm{u}^{+}=\frac{\overline{\left(\mathrm{u}^{2}\right)^{0.5}}}{\mathrm{U}}$, where $\mathrm{u}^{\prime}$ is the fluctuation of $\mathbf{u}$ at different radial sections and $U$ is the entrance average

flow velocity, the region surrounded along with $30 \mathrm{~cm}$ radial distance and $10 \mathrm{~cm}$ vertical distance from basin center is a zone that the turbulence intensity was higher than other zones. It was because of high velocity fluctuations around central flushing orifice. On the other hands by eliminating the influence of entrance flow jet and exiting overflow jet (in the sections that directly affected with them), it would be concluded that the velocity fluctuation (turbulence intensity) of flow around central air core is more than other regions. But the magnitude of mentioned intensity is higher just around flushing orifice.

At the sections of A, B and C an unusual increase of turbulence intensity is shown around side wall of the basin that is direct resultant of entrance flow jet (introduced to basin in lower elevation) and overflow exiting jet (exited from higher elevations).

Another conclusion that could be obtained from Fig. 5, is the higher magnitude of turbulence intensity above the basin bed rather than upper elevations due to influence of basin bed in velocity fluctuation.

The radial distribution of normalized transverse turbulent intensity components $\mathrm{v}^{+}=\frac{\left(\overline{\mathrm{v}^{2}}\right)^{0.5}}{\mathrm{U}}$ where $\mathrm{v}^{\prime}$ is the fluctuation of $\mathbf{v}$ at different radial sections (calculated like u component). And the vertical turbulent intensity components $\mathrm{w}^{+}=\frac{\overline{\left(\mathrm{w}^{\prime 2}\right)^{0.5}}}{\mathrm{U}}$ where $\mathrm{w}^{\prime}$ is the fluctuation of $\mathbf{w}$ at different radial sections (calculated like $\mathbf{u}, \mathbf{v}$ components) also computed and it was found that The distribution pattern of $\mathrm{v}^{+}, \mathrm{w}^{+}$are almost similar in nature to that of $\mathrm{u}^{+}$. However, propagation of higher magnitudes of turbulence intensity in transverse and vertical components is extensive due to the formation of powerful secondary currents in radial sections.

In fluid dynamics, turbulence kinetic energy (TKE) is the mean kinetic energy per unit mass associated with eddies in turbulent flow. Physically, the turbulence kinetic energy is characterized by measured root-mean-square (RMS) velocity fluctuations. TKE can be produced by fluid shear, friction or buoyancy, or through external forcing at low-frequency eddy scales. The cumulative effect of $\mathrm{u} 0, \mathrm{v}^{+}$and $\mathrm{w}^{+}$is reflected in normalized vertical distribution of TKE $\hat{\mathrm{K}}=\frac{\mathrm{k}}{\mathrm{U}^{2}}=0.5 \times\left(\mathrm{u}^{+2}+\mathrm{v}^{+2}+\mathrm{w}^{+2}\right)$, where $\hat{\mathrm{K}}$ is the turbulent kinetic energy at different radial sections (Fig. 5). It is also normalized by average entrance velocity $\mathrm{U}$ introduced to the basin. As is illustrated, it is evident that the most turbulent regions occur along the central air core and high absolute velocity flow area. It is interesting to note that the distribution of TKE along the different radial sections is asymmetric and is dependent to other boundary conditions. Generally it could be mention that in the sections having affected by entrance flow jet and exiting jet (B, C and D), the higher turbulence take place near the chamber sidewall. On the other hands, overall influence of identified intensities $\hat{\mathrm{K}}$ is same as individually of them and follows up foresaid trend.

\section{CONCLUSION}

Unlike classical settling basins, the vortex settling basin needs for higher inlet velocity to maintain a higher hydraulic and removal efficiencies. Therefore an increase in the incoming velocity generates a powerful centrifugal forced vortex causing a better formation of central air core with smaller flushing ring diameter which results in higher hydraulic and extraction efficiencies of the basin. In this research by computation of turbulence components, a new approach was developed to observe the critical and effective regions of basin in sediment extraction processes. As compared by previous research of authors [10], it was observed that the intensity and position of generated flow patterns are different by changing entrance velocity. But like previous research all of generated flow patterns may impose either positive or negative role in sediment trapping. The normalized absolute time averaged velocity $(\hat{V})$ were selected as index velocity of basin in every point. But because of higher magnitude of $u$ component, the influence of it on $\hat{v}$ is higher than other two components $(\mathrm{v}, \mathrm{w})$. The turbulent kinetic energy (TKE) was selected as index of turbulence components and the general trend was interpreted using it. It was observed that the most turbulent regions occur along the central air core and high absolute velocity flow area (like the region around entrance/exit jets). Also the distribution of TKE along the different radial sections was asymmetric, depending to other basin boundary conditions. 


\section{Notation}

$B=$ Width of the inlet canal (m).

$d=$ Diameter of the basin $(\mathrm{m})$.

$d_{o}=$ Diameter of central orifice $(\mathrm{m})$.

$g=$ Acceleration due to the gravity $\left(\mathrm{m} / \mathrm{s}^{2}\right)$.

$H=$ Height of circular basin (m).

$h=$ Vertical distance from the basin floor $(\mathrm{m})$.

$h_{l}=$ Distance between diaphragm and inlet canal bed (m).

$h_{2}=$ Chamber depth at its periphery from inlet canal bed $(\mathrm{m})$.

$h_{p}=$ Depth of flow at the periphery of vortex basin (m).

$L_{1} \quad=\quad$ Length of overflow weir (m).

$R=$ Radius of basin (m).

$r_{o}=$ Radius of flushing orifice $(\mathrm{m})$.

$S_{c}=$ Radial slope of the basin floor (\%).

$\theta=$ Angular distance (degree).

$v=$ Kinematics viscosity of fluid $\left(\mathrm{m}^{2} \mathrm{~s}^{+}\right)$.

$\mathrm{k}=$ Turbulent kinetic energy $\left(\mathrm{m}^{2} \mathrm{~s}^{-2}\right)$

$\hat{\mathrm{K}}=\frac{\mathrm{k}}{\mathrm{U}^{2}}=0.5 \times\left(\mathrm{u}^{+2}+\mathrm{v}^{+2}+\mathrm{w}^{+2}\right)$ : Turbulence kinetic energy

$\mathrm{U}=$ Average entrance velocity $\left(\mathrm{m} \mathrm{s}^{-1}\right)$

$\hat{\mathrm{u}}=\frac{\mathrm{u}}{\mathrm{U}}$ : The normalized $\mathrm{u}$ component

$\mathrm{u}_{+}=$Shear velocity of approaching flow $\left(\mathrm{m} \mathrm{s}^{-1}\right)$

$\mathrm{u}_{+}=\frac{\overline{\left(\mathrm{u}^{\prime 2}\right)^{0.5}}}{\mathrm{U}}:$ Turbulence intensity of $\mathrm{u}$ component

$\mathrm{u}^{\prime}=$ Fluctuation of $\mathrm{u}\left(\mathrm{m} \mathrm{s}^{-1}\right)$

$\mathrm{u}, \mathrm{v}, \mathrm{w}=$ Velocity in polar coordinate system $\left(\mathrm{m} \mathrm{s}^{-1}\right)$

$\overline{\mathrm{V}}=\sqrt{\hat{\mathrm{u}}^{2}+\hat{\mathrm{v}}^{2}+\hat{\mathrm{w}}^{2}}$ : The normalized time averaged absolute velocity

$\hat{\mathrm{v}}=\frac{\mathrm{v}}{\mathrm{U}}:$ The normalized $\mathrm{v}$ component

$\mathrm{v}^{+}=\frac{\left.\overline{\left(\mathrm{v}^{2}\right.}\right)^{0.5}}{\mathrm{U}} \quad$ Turbulence intensity of $\mathrm{v}$ component

$\mathrm{v}^{\prime}=$ Fluctuation of $\mathrm{v}\left(\mathrm{m} \mathrm{s}^{-1}\right)$

$\hat{\mathrm{w}}=\frac{\mathrm{w}}{\mathrm{U}}:$ The normalized $\mathrm{w}$ component

$\mathrm{w}^{+}=\frac{\overline{\left(\mathrm{w}^{\prime 2}\right)^{0.5}}}{\mathrm{U}} \quad$ Turbulence intensity of $\mathrm{w}$ component

$\mathrm{w}^{\prime}=$ Fluctuation of $\mathrm{w}\left(\mathrm{m} \mathrm{s}^{-1}\right)$

\section{REFERENCES}

1. Gard, R.J. and K.G. Ranga Raju, 2000. Mechanics of sediment transportation and alluvial stream problems, $3^{\text {rd }}$ Edn. New Age International, New Dehli, India.

2. Ziaei., A.N., M. Javan and A.L. Keshavarzi, 2001. A new feature of vortex settling basin (VSB). In Proceedings of International Conference on Hydraulic Structures, Kerman, Iran, 3: 41-54.

3. Athar, M., U.C. Kothyari and R.J. Garde, 2002. Sediment removal efficiency of vortex chamber type sediment extractor. J. Hyd. Engng, 128(2): 1051-1059.

4. Mashauri, D.A., 1986. Modeling of vortex settling chamber for primary clarification of water, $\mathrm{PhD}$ thesis, Tampere University of Technology, Tampere, Finland, pp: 217.

5. Salakhov, F.S., 1975. Rotational design and methods of hydraulic calculation of load-controlling water intake structures for Mountain Rivers. Proceedings of Ninth Congress of the ICID, Moscow, Soviet Union, pp: 151-161.

6. Chrysostomou, V., 1983. Vortex-type settling basin, thesis presented to the University of Southampton, at Southampton, England, in partial fulfillment of the requirements for the degree of Master of Science.

7. Rea, Q., 1984. Secondary currents within the circulation chamber sediment extractor, thesis presented to the University of Southampton, at Southampton, England, in partial fulfillment of the requirements for the degree of Master of Science.

8. Cecen, K. and N. Akmandor, 1973. Circular settling basins with horizontal floor. MAG Report No 183, TETAK, Ankara, Turkey.

9. Keshavarzi., A.R. and A.R. Gheisi, 2006. Trap efficiency of vortex settling basin for exclusion of fine suspended particles in irrigation canals. J. Irrigation and Drainage Engng., 55(4): 419-434.

10. Chapokpour, J. and J. Farhoudi, 2011. Sediment extraction and flow structure of vortex settling basin. WASJ, 14(5): 782-793.

11. Paul., T.C., S.K. Sayal, V.S. Sakhanja and G.S. Dhillon, 1991. Vortex settling chamber design considerations. J. Hyd. Engng., 117(2): 172-189. 